\title{
Angiotensin-Il acute regulation of rapid response genes in human, bovine, and rat adrenocortical cells
}

\author{
Edson F Nogueira ${ }^{1}$, Claudia A Vargas ${ }^{1}$, Mélissa Otis ${ }^{3}$, Nicole Gallo-Payet ${ }^{3}$, Wendy B Bollag ${ }^{2}$ \\ and William E Rainey ${ }^{1}$ \\ ${ }^{1}$ Department of Physiology and ${ }^{2}$ Institute of Molecular Medicine and Genetics, Medical College of Georgia, Augusta, Georgia 30912, USA \\ ${ }^{3}$ Service of Endocrinology, University of Sherbrooke, Sherbrooke, Québec J1H 5N4, Canada \\ (Correspondence should be addressed to W E Rainey who is now at Department of Physiology, Medical College of Georgia, 1120 15th Street, CA Building, Room 3094, Augusta, \\ Georgia 30912, USA; Email: wrainey@mail.mcg.edu)
}

\begin{abstract}
Angiotensin-II (Ang-II) regulates adrenal steroid production and gene transcription through several signaling pathways. Changes in gene transcription occur within minutes after Ang-II stimulation, causing an increase in aldosterone production and subsequent increase in the overall capacity to produce aldosterone. Our goal was to compare the Ang-II regulation of early gene expression and confirm the up-regulation of selected genes using quantitative real-time RT-PCR (qPCR) across three species, such as, human, bovine, and rat. Microarray analyses were performed using samples from control and Ang-II $(10 \mathrm{nM})$-treated $(1 \mathrm{~h})$ cells from human adrenocortical tumor cell line H295R, and primary adrenal glomerulosa cells from bovine and rat, applied respectively to human, bovine, and rat chips. qPCR was performed to confirm up-regulation of selected genes using mRNA. The microarray comparison revealed $18 \%$ similarity among the top 50 up-regulated genes, with human/rat, 20\%; human/bovine, 36\%; and rat/bovine, $26 \%$ similarity. The gene list generated by this comparison included: activating transcription factor 3, B-cell translocation gene (BTG2), Nuclear receptor subfamily 4, group A, member 1 (NR4A1), NR4A2, NR4A3, early growth response 1, v-fos FBJ murine osteosarcoma viral oncogene homolog (c-FOS), FOSB, and Jun family member B (JUNB). Pretreatment of H295R cells with cycloheximide had no effect on Ang-II induction of these genes, suggesting that they are direct targets of Ang-II signaling. The Ang-II gene targets have been defined in three different adrenocortical model systems. Several of the listed genes have previously been described as being key regulators of adrenocortical function. The presence of adrenal cell common genes in such distinct cell models strengthens the hypothesis that these genes are regulators of aldosterone production.
\end{abstract}

Journal of Molecular Endocrinology (2007) 39, 365-374

\section{Introduction}

The renin-angiotensin-aldosterone system is a central component of the hormonal mechanisms that regulate blood pressure. Angiotensin-II (Ang-II) is the most potent stimulus of aldosterone secretion and is known to be a growth factor for adrenal glomerulosa cells, stimulating cell proliferation, at least under in vivo conditions. The effect of Ang-II on aldosterone secretion is mediated through type 1 Ang-II (AT1) receptors (Spat \& Hunyady 2004) and is largely due to activation of the $\mathrm{G}_{\mathrm{q}}$ /phospholipase $\mathrm{C}$ (PLC)-dependent hydrolysis of phosphatidylinositol 4,5-bisphosphate, leading to production of inositol phosphates and diacylglycerol (Guillon et al. 1995). The AT1 receptor is a G proteincoupled receptor that associates with $G_{i}, G_{o}$, and $G_{q}$ thereby activating PLC, phospholipase D (PLD), and phospholipase $\mathrm{A}_{2}$ (PLA 2 ; Hunyady \& Catt 2006). As are several other $\mathrm{G}$ protein-coupled receptors, Ang-II is able to activate the mitogen-activated protein (MAP) kinases pathway, namely $\mathrm{p} 42 / \mathrm{p} 44^{\mathrm{mapk}}$ (also called extracellular signal-regulated kinase (ERK) 1/2) in bovine (Chabre et al. 1995) and rat (Cote et al. 1998, McNeill et al. 1998). In addition, AT1 receptors can signal through G proteinindependent pathways including Janus kinases/signal transducers and activaters of transcription (Jak/STAT) and the epidermal growth factor (EGF) receptor (Seta et al. 2002). Stimulation of these pathways leads to a range of downstream effects, including activation of calcium/ calmodulin-dependent kinase, PLD, $\mathrm{PLA}_{2}$, protein kinase C, src tyrosine kinases, and MAP kinases (Hunyady \& Catt 2006, Mehta \& Griendling 2007). These diverse pathways influence adrenal glomerulosa cell division, acute aldosterone production, and the capacity of adrenal cells to produce aldosterone chronically (Otis et al. 2007). Many of the effects of Ang-II on the adrenal cells are thought to be related to Ang-II-induced changes in gene transcription (Naville et al. 2001, Li et al. 2003, Bassett et al. 2004a, Romero et al. 2007).

Many of the effects of Ang-II relate to the induction of a group of 'rapid' response genes, which include the nerve growth factor-induced clone B (NGFIB), v-fos FBJ murine osteosarcoma viral oncogene homolog (FOS), JUN, and early growth response (EGR) families of 
transcription factors. These genes respond to Ang-II treatment in a variety of tissues including smooth muscle, brain, and cardiac myocytes, as well as the adrenal gland (Sadoshima \& Izumo 1993, Herbert 1996, McKay et al. 1998). In vitro and in vivo studies of Ang-II action in the adrenal have shown that several rapid response genes are involved in steroidogenesis as well as adrenal cell growth and differentiation. Although adrenal glomerulosa cells represent the primary adrenal cell target for Ang-II, no studies have been performed to define their Ang-II rapid response genes.

Ang-II gene targets in glomerulosa cells have only been defined in one cell culture model, the H295R adrenal carcinoma cell line (Romero et al. 2004). This cell line is of human origin, grows well in culture, expresses AT1 receptors, and responds to Ang-II with increased aldosterone production and aldosterone synthase (CYP11B2) expression (Gazdar et al. 1990, Bird et al. 1993, 1994, Rainey et al. 2004). However, these cells, like their parental tumor, also produce large amounts of cortisol and dehydroepiandrosterone (DHEA)-sulfate (Rainey et al. 1993). Thus, they have retained some characteristics of each of the human adrenocortical zones and do not represent a specific model for the zona glomerulosa (Rainey et al. 1994, 2004, Bollag et al. 2007). There are two additional primary glomerulosa cell culture models (bovine and rat adrenal in origin) that are widely used to study Ang-II receptors and aldosterone production (Aguilera 1992, Lu et al. 1996, Bollag et al. 2007). Because of the non-specific zonal nature of the H295R adrenocortical carcinoma cell model, the current study was undertaken to compare the Ang-II gene targets between the H295R cells and the two other common glomerulosa cell models. Thus far, such cross species comparison of Ang-II target genes has not been performed.

\section{Materials and methods}

\section{Cell culture and treatments}

NCI-H295R (H295R) human adrenocortical tumor cells were cultured in modified Eagle's medium (DME)/ Ham's F12 medium (Invitrogen) supplemented with $10 \%$ cosmic calf serum (Hyclone, Logan, UT, USA), $1 \%$ penicillin/streptomycin (Invitrogen), and $0.01 \%$ gentamicin (Invitrogen). Cells were maintained in a $37^{\circ} \mathrm{C}$ humidified atmosphere $\left(5 \% \mathrm{CO}_{2}\right)$. Cells were subcultured into six-well culture dishes (Corning Costar, Corning, NY, USA) at a density of 1200000 cells/well for subsequent treatments and RNA isolation. Prior to treatments, adrenal cells were maintained overnight in low-serum medium (DME/Ham's F12 medium supplemented with $0 \cdot 1 \%$ cosmic calf serum medium, $1 \%$ penicillin/streptomycin, and $0.01 \%$ gentamicin).
In addition, cells were pre-incubated with or without $35 \mu \mathrm{M}$ cycloheximide ( $15 \mathrm{~min})$ and then stimulated with or without $10 \mathrm{nM}$ Ang-II for $1 \mathrm{~h}$.

The bovine adrenal glomerulosa cells were isolated from male and female near-term fetal calves and cultured overnight in Falcon Primaria dishes (Becton Dickinson Labware, Lincoln Park, NJ, USA) in a DME/Ham's F12 medium (1:1) containing 10\% horse serum (vol/vol), $2 \%$ fetal bovine serum (vol/vol), $100 \mu \mathrm{M}$ ascorbate, $1 \cdot 2 \mu \mathrm{M}$ $\alpha$-tocopherol, $0.05 \mu \mathrm{M} \mathrm{Na}_{2} \mathrm{SeO}_{3}, 50 \mu \mathrm{M}$ butylated hydroxyanisole, $5 \mu \mathrm{M}$ metyrapone, $100 \mathrm{U} / \mathrm{ml}$ penicillin, $100 \mu \mathrm{g} / \mathrm{ml}$ streptomycin, and $0 \cdot 25 \mu \mathrm{g} / \mathrm{ml}$ amphotericin B. After replacement of the serum-containing medium with serum-free medium $(+0 \cdot 2 \% \mathrm{BSA})$, the cells were incubated for an additional 20-24 h before use. The cells were then rinsed with bicarbonate-buffered Krebs-Ringer solution containing $2.5 \mathrm{mM}$ sodium acetate (KrebsRinger buffer $(\mathrm{KRB})+$ ) and incubated for $30 \mathrm{~min}$ (in $\left.5 \% \mathrm{CO}_{2}\right)$ in $\mathrm{KRB}+$ before addition of $\mathrm{KRB}+$ with or without $10 \mathrm{nM}$ Ang-II. After an additional 1-h incubation, supernatants were collected and frozen for subsequent RIA of aldosterone (Diagnostic products, Los Angeles, CA, USA). Cells were rinsed once with PBS-lacking divalent cations and immediately placed at $-80^{\circ} \mathrm{C}$ until processing to obtain RNA.

The rat glomerulosa cells were obtained from adrenal glands of female Long-Evans rats weighing 200-250 g and isolated according to the method previously described in detail (Gallo-Payet \& Payet 1989). All protocols were approved by the Animal Care and Ethics Committee of the Université de Sherbrooke. Isolation and cell dissociation of the zona glomerulosa was performed in MEM medium, supplemented with $100 \mathrm{U} / \mathrm{ml}$ penicillin and $100 \mu \mathrm{g} / \mathrm{ml}$ streptomycin. After a 20-min incubation at $37^{\circ} \mathrm{C}$ with collagenase $(2 \mathrm{mg} / \mathrm{ml})$ and DNase $(25 \mu \mathrm{g} / \mathrm{ml})$, cells were dispersed by gentle aspiration with a sterile $10 \mathrm{ml}$ pipette, filtered, and centrifuged for $10 \mathrm{~min}$ at $1200 \mathrm{~g}$. The cell pellet was then resuspended in OPTI-MEM medium supplemented with 2\% FBS (fetal bovine serum), $100 \mathrm{U} / \mathrm{ml}$ penicillin, and $100 \mu \mathrm{g} / \mathrm{ml}$ streptomycin. Glomerulosa cells were plated at a density of $6 \times 10^{5}$ cells/Petri dish and were cultured at $37^{\circ} \mathrm{C}$ in a humidified atmosphere composed of $95 \%$ air $/ 5 \% \mathrm{CO}_{2}$. Glomerulosa cells were stimulated with $10 \mathrm{nM}$ Ang-II for $1 \mathrm{~h}$.

\section{Microarray analysis}

RNA from H295R cells was hybridized to an Affymetrix human HG_U133+2 oligonucleotide microarray set containing 54675 probe sets representing $\sim 40500$ independent human genes. The arrays were scanned at high resolution in the microarray core facility at the Medical College of Georgia in Augusta, GA. RNA samples isolated from bovine and rat adrenal glomerulosa cells stimulated for $1 \mathrm{~h}$ with Ang-II versus basal were shipped to Codon Biosciences (Houston, TX, USA) for hybridization 
with bovine array (24 128 probe sets) and Rat230_2 chip (31 095 probe sets) respectively. Results were analyzed using GeneSpring software version 7·3 (Silicon Genetics, Redwood City, CA, USA) to identify differences in expression of genes after treatment with Ang-II for $1 \mathrm{~h}$ compared with basal, and cycloheximide compared with cycloheximide+Ang-II. Microarray data imported into GeneSpring software were normalized using RMA (robust multichip average) followed by an additional normalization to the 50th percentile of all signal values.

\section{RNA extraction, cDNA synthesis, and real-time RT-PCR}

Total RNA was extracted from cells plates using Trizol (Invitrogen) according to the manufacturer's directions. Quantification, purity, and integrity of the RNA were checked spectroscopically using Nanodrop (Nanodrop Technologies, Wilmington, DE) and Experion (Bio-Rad Laboratories) instruments. DNase I (2 $\mu \mathrm{g}$; Ambion Inc., Austin, TX, USA)-treated total RNA was reverse transcribed using the high-capacity cDNA archive kit (Applied Biosystems, Foster City, CA, USA) following the manufacturer's recommendations. Primers for the amplification of the target sequences were designed using Primer Express 3.0 (Applied Biosystems). The sequences are shown in Supplementary Table 1 , which can be viewed online at http://jme. endocrinology-journals.org/content/vol39/issue6/.

PCR amplifications were performed using the ABI Prism 7500 sequence detection system (Applied Biosystems) following the reaction parameters recommended by the manufacturer, using $2 \mu \mathrm{g}$ RNA per sample. For rat and bovine samples, the $30 \mu \mathrm{l}$ total volume consisted of SYBR Green universal PCR master mix (2×; Applied Biosystems), forward and reverse primer mix, and $5 \mu \mathrm{l}$ cDNA. For human samples, the $20 \mu \mathrm{l}$ total volumes consisted of Fast Reagent Master Mix (Applied Biosystems), primer/probe mix, and $5 \mu \mathrm{l}$ cDNA. $18 \mathrm{~s}$ was used as an endogenous control gene and negative controls contained water instead of cDNA.

In all experiments, relative gene expression was calculated by the $\Delta \Delta C_{\mathrm{t}}$ method. Briefly, the resultant mRNA was normalized to a calibrator; in each case, the calibrator chosen was the basal sample. Final results were expressed as the $n$-fold difference in gene expression relative to $18 \mathrm{~s}$ rRNA and calibrator as follows: $n-$ fold $=2^{-\left(\Delta C_{\mathrm{t}} \text { smple }-\Delta C_{\mathrm{t}} \text { basal }\right)}$, where $\Delta C_{\mathrm{t}}$ values of the sample and calibrator were determined by subtracting the average $C_{\mathrm{t}}$ value of the transcript under investigation from the average $C_{\mathrm{t}}$ value of the 18s rRNA gene for each sample.

\section{Statistical analysis}

For qPCR analysis, all values were expressed as mean \pm s.e.M. Statistical calculations were performed with
Ms Office Excel 2003 (Microsoft Corporation). Statistical differences between qPCR samples were determined by Student's $t$-test. $P<0.05$ was required for statistically significance.

\section{Results}

\section{Ang-II target genes in human H295R cells}

The H295R cell line is the only human adrenal cell model that responds to Ang-II and has been used to study 'acute' and chronic production of aldosterone (Bassett et al. 2000). Adrenal H295R cells were treated for $1 \mathrm{~h}$ with Ang-II $(10 \mathrm{nM})$ followed by isolation of RNA and microarray analysis. Of the 54675 probe sets on the Affymetrix array, 28718 were considered detectable on both the basal and Ang-II samples and these probe sets were used for data analysis. A fivefold increase took place in 16 transcripts, whereas no gene was down-regulated more than fivefold (Fig. 1, Panel A). The genes with the highest fold change were further studied using qPCR from three independent experiments (Fig. 1, Panel B). These replicate experiments confirmed increased expression for each of these genes identified by microarray analysis. Analyses of RNA from Ang-II-treated H295R cells from three different experiments compared with basal showed four transcription factors among the top five up-regulated genes. In order of increased expression determined by microarray analysis, the identified genes are: nuclear receptor subfamily 4, group A, member 2 (NR4A2), FOS, FOSB, NR4A3, and EGR4.

To determine whether genes were direct or indirect targets of Ang-II treatment, the H295R cells were treated with cycloheximide to block new protein synthesis. Array analysis was compared between cells treated with cycloheximide versus those exposed to Ang-II plus cycloheximide. Genes were determined to be detectable on at least one of the arrays and these genes were used for data analysis. More than fivefold increase was found in $80 \%$ of the genes in Fig. 1 (Panel A) which also increased by more than fivefold in the presence of cycloheximide. Of the top 20 genes, 12 genes shown to increase following Ang-II treatment in the absence of cycloheximide were also increased in its presence. These data suggest that a great number of genes that change expression following $1 \mathrm{~h}$ of Ang-II treatment are direct targets of Ang-II signaling pathways and not regulated by the proteins whose expression changes acutely after Ang-II stimulation.

\section{Ang-Il target genes in primary cultures of bovine glomerulosa cells}

Because of the adrenal size and their availability at many abattoirs, bovine adrenals have been used by many 

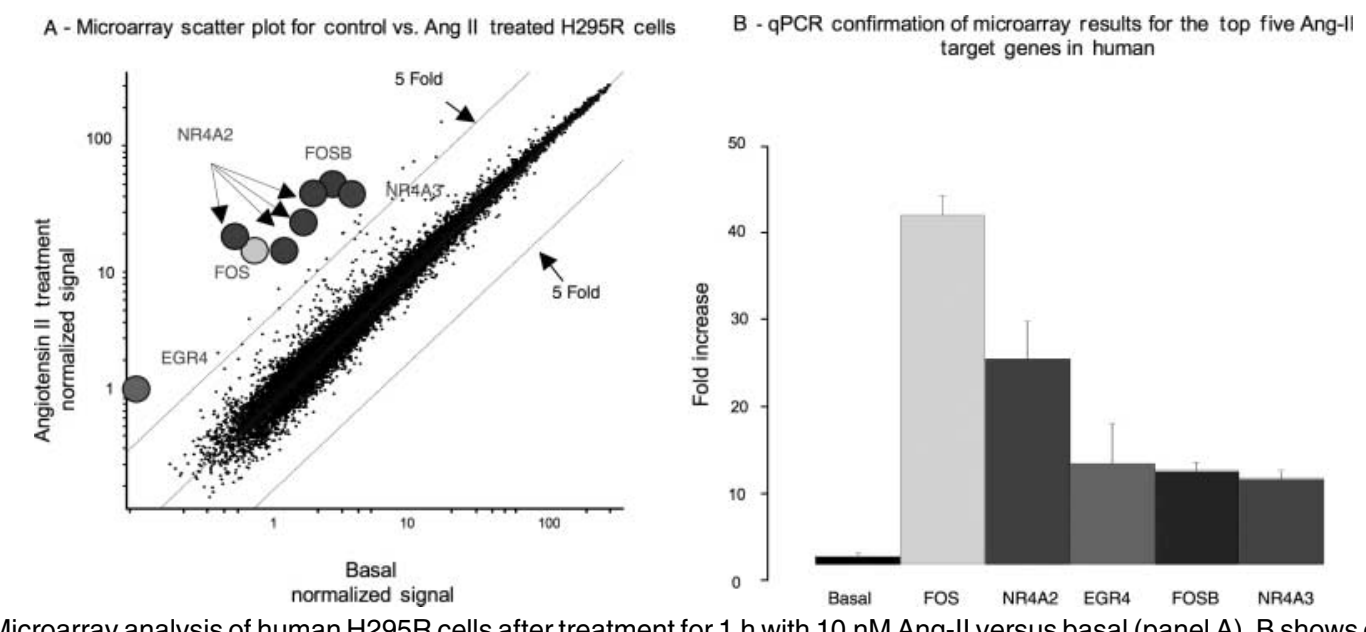
target genes in human

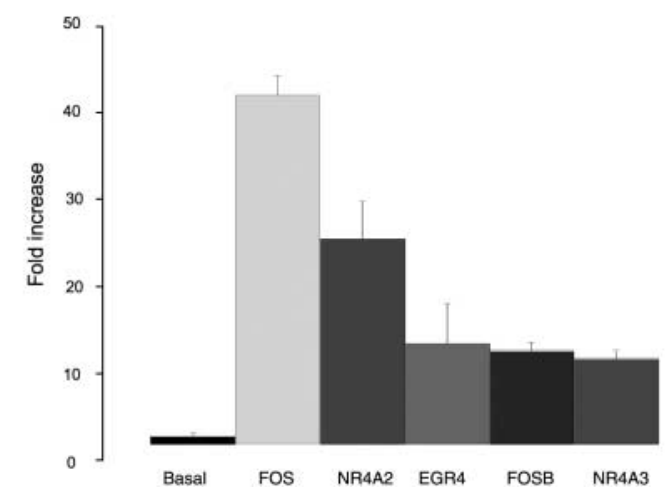

Figure 1 Microarray analysis of human H295R cells after treatment for $1 \mathrm{~h}$ with $10 \mathrm{nM}$ Ang-II versus basal (panel A). B shows confirmation with qPCR of gene up-regulation of the top five genes, which act as transcription factors, with the exception of an unknown sequence (EST). The following abbreviations are conventionally used by the GeneSpring Software: FOS, v-fos FBJ murine osteosarcoma viral oncogene homolog; FOSB, FBJ murine osteosarcoma viral oncogene homolog B. NR4A2, Nuclear receptor subfamily 4, group A, member 2; NR4A3, Nuclear receptor subfamily 4, group A, member 3; EST, expressed sequence tag (unknown sequence). qPCR data represent the mean \pm S.E.M. for three independent experiments. All gene increases were statistically significant from basal levels $(P<0 \cdot 05)$.

groups to isolate Ang-II-responsive glomerulosa cells (Lu et al. 1996, Smith et al. 1998, Cherradi et al. 2003, Bollag et al. 2007). Current arrays for bovine only partially cover the transcriptome with 24128 probe sets. Of these, 13568 were detectable in both basal and Ang-II-treated cells. Among these, seven were increased by more than fivefold upon Ang-II treatment while none decreased by fivefold (Fig. 2, panel A). The primary bovine glomerulosa cell microarray data also showed four transcription factors among the top five up-regulated genes: NR4A3, EST (Genbank: CB431046), NR4A2, FOS, and NR4A1. The qPCR analysis of each gene was performed in three independent bovine glomerulosa experiments (Fig. 2, Panel B). The qPCR showed positive correlation between the fold increase determined in independent experiments and confirmed the results obtained in the microarray analysis.

\section{Ang-II target genes in primary cultures of rat glomerulosa cells}

The rat glomerulosa cell has long been used as a model system for acute Ang-II action (Aguilera 1992, Hajnoczky et al. 1992). Rat adrenal glomerulosa cells were treated for $1 \mathrm{~h}$ with Ang-II $(10 \mathrm{nM})$ followed by isolation of RNA and microarray analysis. Of the 31095 probe sets on the Affymetrix array, 15103 were considered detectable on both the Ang-II-treated and basal samples and these probe sets were used for data analysis. Seven transcripts were increased, and none decreased, by fivefold (Fig. 3, panel A). The five genes with the highest fold change were further studied using qPCR from three independent experiments, which confirmed the stimulatory effects of Ang II
(Fig. 3, panel B). Four of the top five Ang-II induced genes were classified as transcription factors (EGR3, NR4A1, NR4A3, and FOSB) and the fifth was BTG2, a protein involved in cell cycle regulation.

\section{Species comparisons of Ang-II target genes}

A list of the top 50 Ang-II-responsive genes with known functions was generated for the bovine, human, and rat model systems (Supplementary Table 1 which can be viewed online at http://jme.endocrinology-journals. org/content/vol39/issue6/). To determine similarity between the three species, genes were placed in a Venn diagram (Fig. 4). Nine genes or $18 \%$ of the total genes were found to be common across the three species. The nine common genes were: NR4A1, NRA42, NR4A3, FOS, FOSB, JUNB, EGR1, BTG2, and activating transcription factor 3 (ATF3; Table 1). These transcripts encode either transcription factors, nuclear receptors or, in the case of BTG2, a protein that indirectly regulates cell cycle. The predominance and similarity of transcription factor upregulation support the hypothesis that activation of Ang-II receptors rapidly alters gene expression leading to both acute and chronic alterations in the glomerulosa cell phenotype.

\section{Discussion}

For the first time, we report a comparative study of the acute target genes for Ang-II in the most commonly used adrenal cell model systems: the H295R adrenocortical carcinoma cell line, primary bovine glomerulosa cells, and primary rat glomerulosa cells. Previous genomic studies have used the H295R cell model to determine genetic regulation by Ang-II (Romero et al. 2004). It represents the 
A - Microarray scatter plot for control vs. Ang II treated bovine cells

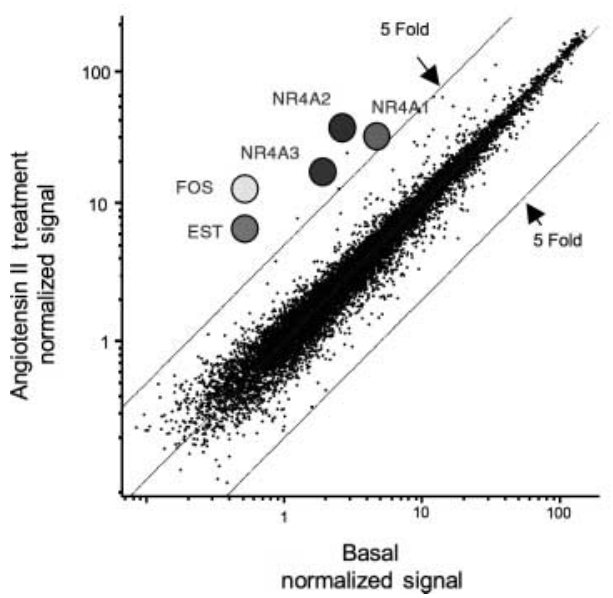

B - qPCR confirmation of microarray results for the top five

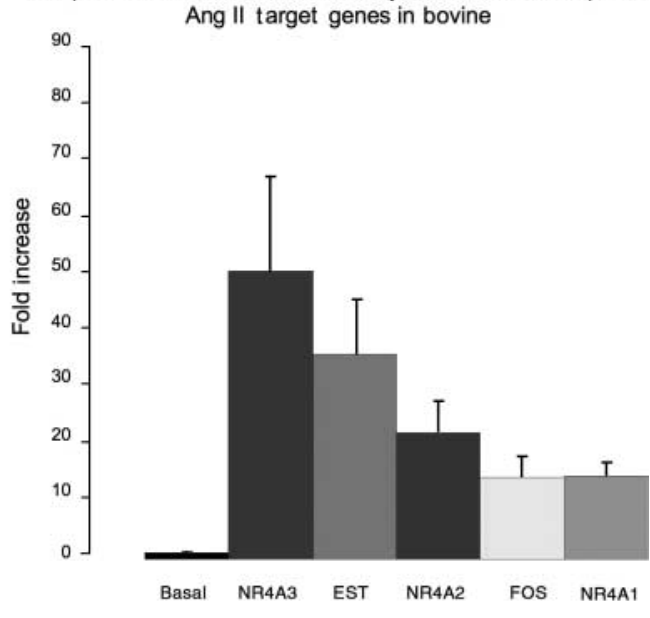

Figure 2 Microarray analysis of bovine glomerulosa cells after 1-h stimulation with $10 \mathrm{nM}$ Ang-II versus basal (panel A). Panel B shows the confirmation of gene up-regulation with qPCR of the selected top five genes, which act as transcription factors, with the exception of an unknown sequence (EST). Abbreviations are as in the legend to Fig. 1. qPCR data represent the mean \pm s.E.M. for three independent experiments. All gene increases were statistically significant from basal levels $(P<0.05)$.

only human adrenal model that responds to Ang-II. However, the H295R exhibits differences from normal glomerulosa cells that support the need for comparison studies with other glomerulosa models. For example, these cells have retained the ability to produce cortisol and DHEA, expressed high levels of the enzyme $17 \alpha$ hydroxylase, and lost their response to adrenocorticotrophin (ACTH; Mountjoy et al. 1994, Bird et al. 1998). Thus, while H295R cells are highly responsive to Ang-II, these cells represent a carcinoma cell line that displays attributes consistent with each of the zones of the adult adrenal as well as some characteristics associated with fetal adrenal cells (Logie et al. 1999). It is for these reasons that we compared the Ang-II target genes found in H295R cells with those observed in two primary cell cultures models arising from bovine and rat zona glomerulosa.

There have been two studies published (one acute and one chronic) that examined Ang-II gene targets in the H295R adrenal cell model (Wang et al. 2000, Romero et al. 2004). Ang-II rapid-response target genes have previously been defined in the H295R human adrenocortical carcinoma cell model using microarray analysis following a 3-h treatment period with Ang-II. Our results follow the results of this longer exposure to Ang-II (below). A comparison of the 50 transcripts from each of the Ang-II-responsive cell models demonstrated an $18 \%$

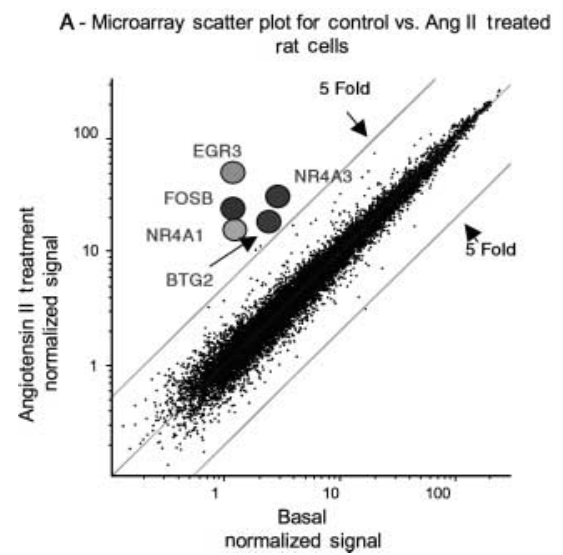
B - qPCR confirmation of microarray results for the top five
Ang II target genes in rat

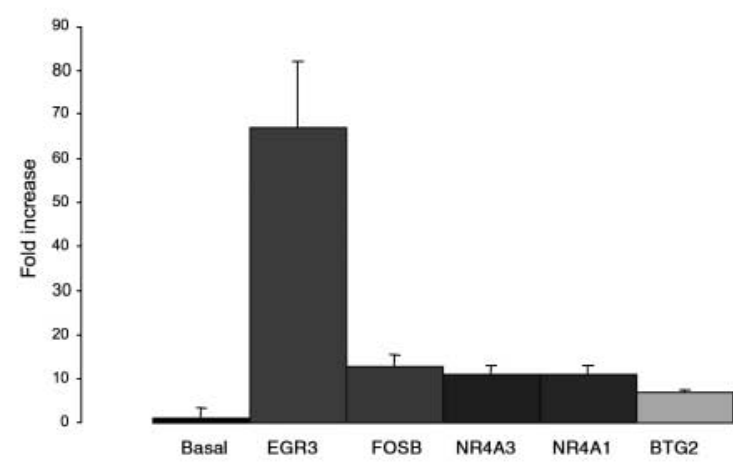

Figure 3 Microarray analysis of rat glomerulosa cells after 1-h stimulation with $10 \mathrm{nM}$ Ang-Il versus basal (panel A). Graph 3B shows the confirmation of gene up-regulation with qPCR of the top five genes, all classified as transcription factors. The abbreviations used are as in the legend for Fig. 1 with the following two additional abbreviations: BTG2 and BTG family, number 2; EGR3, early growth response 3. qPCR data represent the mean \pm S.E.M. for four independent experiments. All gene increases were statistically significant from basal levels $(P<0.05)$. 


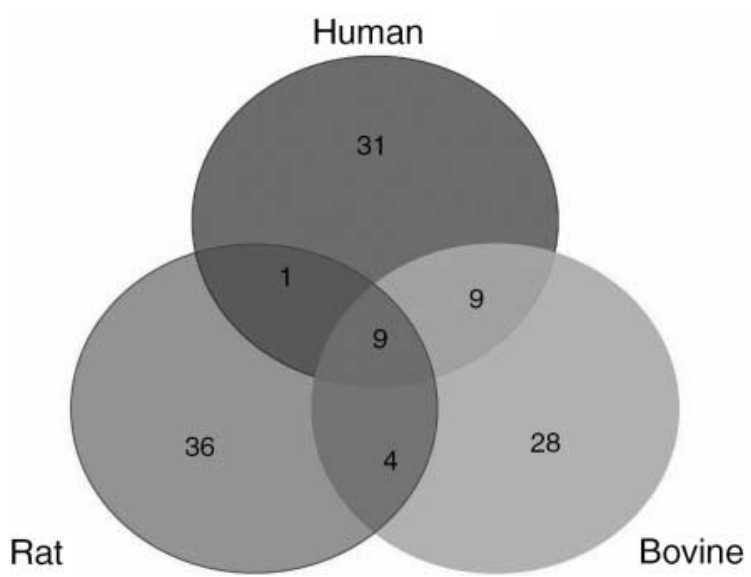

Figure 4 Venn diagram demonstrating the absolute number of common genes among human, bovine, and rat. The list of genes used to make the diagram was based on the top 50 genes (excluding ESTs) that were up-regulated upon in vitro treatment with $10 \mathrm{nM}$ Ang-Il for $1 \mathrm{~h}$ in cells from each of the three adrenal glomerulosa models.

similarity across the three species. Herein, we focused on the genes found to be common between the three model systems. The common genes arranged in Table 1 include three members of the NGFI-B family; JUNB and FOS (members of the AP-1 complex), EGR-1, BTG2 and ATF3. The core group of transcription factors that were elevated in each of our three model systems were in the list of AngII target genes described by Romero et al. (2007) in H295R (3 h Ang-II). Such a common pattern of induction across three species suggests that Ang-II induction of these transcription factors may be necessary for the acute and chronic regulation of glomerulosa cell aldosterone production.

Considerable effort has been expended to define the role of the NR4A family of nuclear hormone receptors in the regulation of adrenal cell steroid production. These transcription factors are members of the nuclear receptor family but have no identified ligand. They regulate transcription through changes in their expression level and phosphorylation (Hsu et al. 2004, Maxwell \& Muscat 2006). Previous studies using rat, bovine, human, and mouse adrenal models have identified members of the NR4A family of nuclear hormone receptors as adrenocortical rapid response genes that increase after Ang-II or ACTH treatment (Enyeart et al. 1996, Fernandez et al. 2000, Kelly et al. 2004). These nuclear receptors have also been shown to increase adrenal-specific gene expression in several whole animal studies suggesting that our in vitro observations may have physiologic significance (Pirih et al. 2005, Pei et al. 2006). Additional studies have focused on defining the functional role of NR4A1 (previously called Nurr77, or NGFI-B, NR4A2 (previously called Nurr1) and NR4A3 (previously called Nor1) in adrenal steroidogenesis (Crawford et al. 1995, Fernandez et al. 2000, Lu et al. 2004). In the H295R cells, NR4A1 and NR4A2 appear to increase selectively the expression of enzymes involved in aldosterone and cortisol biosynthesis. NR4A2 and NR4A1 have selective effects on CYP11B2 and HSD3B2 transcription (Bassett et al. 2004b); however, no effect was observed on the transcription of CYP11B1 or CYP17. A recent study confirmed a stimulatory effect

Table 1 Common angiotensin-II (Ang-II) target genes across the human, bovine, and rat adrenal models systems

\begin{tabular}{|c|c|c|c|c|c|}
\hline & Gene function & Name & $\begin{array}{l}\text { Human mean fold } \\
\text { increase over } \\
\text { basal }\end{array}$ & $\begin{array}{l}\text { Bovine mean fold } \\
\text { increase over } \\
\text { basal }\end{array}$ & $\begin{array}{l}\text { Rat mean fold } \\
\text { increase over } \\
\text { basal }\end{array}$ \\
\hline Activating transcription factor 3 & Transcription factor & ATF3 & $2 \cdot 63$ & $2 \cdot 5$ & 2.98 \\
\hline BTG family, member 2 & Modulator of cell cycle & BTG2 & $6 \cdot 64$ & $7 \cdot 12$ & $5 \cdot 65$ \\
\hline Early growth response 1 & Transcription factor & EGR1 & $9 \cdot 30$ & $2 \cdot 94$ & $3 \cdot 77$ \\
\hline Jun B proto-oncogene & Transcription factor & JUNB & $4 \cdot 88$ & $3 \cdot 20$ & $2 \cdot 41$ \\
\hline $\begin{array}{l}\text { Nuclear receptor subfamily } 4 \text {, } \\
\text { group } A \text {, member } 1\end{array}$ & Nuclear receptor & NR4A1 & $5 \cdot 4$ & 3.02 & $16 \cdot 08$ \\
\hline $\begin{array}{l}\text { Nuclear receptor subfamily } 4 \text {, } \\
\text { group A, member } 2\end{array}$ & Nuclear receptor & NR4A2 & $30 \cdot 91$ & $10 \cdot 65$ & $4 \cdot 53$ \\
\hline $\begin{array}{l}\text { Nuclear receptor subfamily } 4 \text {, } \\
\text { group } A \text { member } 3\end{array}$ & Nuclear receptor & NR4A3 & $12 \cdot 10$ & $27 \cdot 49$ & $10 \cdot 80$ \\
\hline
\end{tabular}

A list of the most responsive transcripts to $1 \mathrm{~h}$ Ang-II (10 nM) treatment (with known annotation) was compiled for H295R, bovine glomerulosa, and rat glomerulosa cells. Comparison of the top 50 transcripts provided the genes common to each model system. The complete list of the 50 transcripts for each model is available as Supplementary Tables 1, 2, and 3, which can be viewed online at http://jme.endocrinology-journals.org/content/vol39/issue6/. Also listed are the gene functions and fold increase compared with basal expression levels. 
of NR4A1, NR4A2, and NR4A3 on CYP11B2 transcription, using transfection of H295R cells with CYP11B2 reporter constructs (Romero et al. 2007). Others have demonstrated that NR4A1 and NR4A3 regulate transcription of CYP21, which is also needed for aldosterone/cortisol biosynthesis (Wilson et al. 1993, Fernandez et al. 2000). Studies in mouse adrenocortical Y1 cells suggest that regulation of NR4A1 by ACTH occurs via both increased expression and phosphorylation of NR4A1 (Li \& Lau 1997).

Several studies reported a rapid induction of the activating protein 1 (AP-1) factors (FOS and JUN family members) by both Ang-II and ACTH (Viard et al. 1992, Lehoux et al. 1998, Naville et al. 2001). AP-1 complexes function as homo- or heterodimers formed by members of the c-FOS and JUN families. Interaction between members of the two families to form heterodimers leads to a much higher affinity for AP-1 sites. Different AP-1 complexes consisting of different FOS and JUN members display distinct transcriptional regulatory activities in different cell systems (Enyeart et al. 1996). In H295R cells, following co-transfection of c-FOS and FOSB with CYP11B1 or CYP11B2, transcriptional activity of both steroidogenic enzymes was enhanced (Romero et al. 2007). However, a comparison of the fold increases of these two steroidogenic enzymes in the same study has shown greater effects on CYP11B1. This results agrees with studies performed in the rat in which FOS increases rat CYP11B1 transcriptional activity (Mukai et al. 1995), and with the presence of a putative AP-1 site in human CYP11B1 (Rainey 1999).

The EGR family of zinc finger proteins is coordinately stimulated in resting cells upon a growth stimulus. EGR4, which is present in the top five up-regulated genes in H295R cells, is known to be an auto-regulatory protein that causes transcription repression (Zipfel et al. 1997). In rat glomerulosa cells, the EGR3 was the gene that demonstrated the greatest 1-h stimulation by Ang-II. EGR3 was previously shown to be increased in the adrenal cortex of rats following stress induced by capsaicin infusion (Honkaniemi et al. 2000). This increase was thought to result from increased ACTH levels and was not affected by denervation of the adrenal medulla. Another EGR family member, EGR1, was up-regulated in human, bovine, and rat arrays, although it was not among the top five genes. Because of the known role of EGR1 and EGR3 in activating cell division, it is likely that these factors may be responsible for the known action of Ang II on adrenal glomerulosa cell division.

The ATF1, has been previously described by $\mathrm{Gu}$ and colleagues as a part of the pathway activating aldosterone synthase expression following Ang-II treatment of H295R cells (Gu et al. 2003). Also, interaction of ATF1 and ATF2 with the cAMP-responsive element (CRE) was shown within the promoters of CYP11B1 and CYP11B2 in H295R cells (Bassett et al. 2004c). No previous studies were found to connect ATF3 with Ang-II or ATF3 with the adrenal. However, ATF3 is known to bind CRE within other target genes and therefore could play a role in CYP11B1 and CYP11B2 transcription (Liang et al. 1996).

Several interesting genes were increased in each of the three in vitro models, but not to a level placing them in the top 50 genes (Supplementary Tables 2-3, which can be viewed online at http://jme.endocrinologyjournals.org/content/vol39/issue6/). For example, regulator of G-protein signaling 2 (RGS2) was in the top 50 up-regulated genes in rat and bovine. In the human, RGS2 has previously been described as a regulator of AT1-receptor signaling in adrenocortical cells (Romero et al. 2006). Over-expression of the RGS2 gene decreases the Ang-II-induced synthesis of aldosterone. MAP phosphatase-1 (MKP-1), also called dual specificity phosphatase 1 , was up-regulated in all the three adrenal models and was one of the top ten AngII-responsive genes for human and bovine cells. In a recent study using bovine adrenal glomerulosa cells, Ang-II was also shown to induce expression of MPK-1. Interestingly, MPK-1 over-expression was shown to cause inactivation of ERK1/2, leading to a decrease in mineralocorticoid production (Casal et al. 2007). In contrast, Ang-II activation of ERK1/2 has been shown to play an important role in the activation of rat adrenal glomerulosa cell aldosterone production (Otis \& Gallo-Payet 2006). Taken together, these results suggest that the synthesis of MKP-1 works as an intracellular negative feedback mechanism to dampen Ang-II action. nuclear factor, interleukin 3 (NFIL3) regulated) is also included in the list of up-regulated genes in the three species. NFIL3 has been previously identified as a transcription factor with defined roles in cell survival (Cowell 2002). With regard to the adrenal, a previous study identified NFIL3 as one of the genes responsive to Ang-II treatment of H295R cells (Romero et al. 2007). Furthermore, studies suggested that NFIL3 regulates CYP11B2 transcription (10). Interestingly, few mRNAs encoding steroidogenic enzymes changed in the 1-h treatment period with Ang-II. CYP21A1 was increased by approximately threefold in rat glomerulosa cells, and steroidogenic regulatory protein (StAR) mRNA was one of the top 10 genes increased in bovine adrenal cells. The functional role of this protein in the acute transport of cholesterol inside the mitochondria suggests that the bovine glomerulosa system may be more acutely coupled than either the rat or human adrenal cell model.

Although Ang-II plays critical roles in numerous physiological processes, there have been few studies directed at defining its target genes using microarray analysis. Vascular smooth muscle cell Ang-II targets were examined using filter arrays containing $\sim 5000$ genes (Braam et al. 2003, Campos et al. 2003). In addition, Ang-II 
target genes were studied in human renal proximal tubular cells using targeted filter arrays that contained 287 genes (Braam et al. 2003). While it is difficult to directly compare these studies with our study, it is interesting that none of the transcripts observed in the vascular smooth muscle or proximal tubular cells were observed in the top 50 genes observed to change in the adrenal cell models. However, future studies using a similar microarray format would be useful to better determine if there are common gene targets.

In summary, the effects of Ang-II on aldosterone biosynthesis can be divided into acute and chronic phases. Acutely (minutes to hours after a stimulus), aldosterone production is controlled by the movement of cholesterol into the mitochondria, which is mediated by post translational modification of and increased expression of StAR protein (Christenson \& Strauss 2001). Chronically (hours to days), aldosterone production is regulated at the level of steroid-metabolizing enzymes including aldosterone synthase (CYP11B2; Bassett et al. 2004a). Considerable evidence suggests that the acute and chronic phases of aldosterone production rely on the transcription of target genes and their translation to proteins. Herein, the acute target genes for Ang-II were defined in the three most commonly used adrenal cell model systems: the H295R adrenocortical carcinoma cell line, primary bovine glomerulosa cells, and primary rat glomerulosa cells. All three models responded to Ang-II stimulation with expression of a variety of transcription factors that we hypothesize are responsible for converting the transient ligand/receptor signal into lasting changes in the phenotype of the cell and its capacity to produce steroids.

\section{Acknowledgements}

This work was supported by National Institute of Health grant DK43140 to WER and HL70046 to WBB. The authors declare that there is no conflict of interest that would prejudice the impartiality of this scientific work. Data deposition: Microarray data have been deposited in the NCBI/GEO database under the accession number GSE8442.

\section{Disclosures}

The authors have nothing to disclose.

\section{References}

Aguilera G 1992 Role of angiotensin II receptor subtypes on the regulation of aldosterone secretion in the adrenal glomerulosa zone in the rat. Molecular and Cellular Endocrinology 90 53-60.

Bassett MH, Zhang Y, White PC \& Rainey WE 2000 Regulation of human CYP11B2 and CYP11B1: comparing the role of the common CRE/Ad1 element. Endocrine Research 26 941-951.
Bassett MH, White PC \& Rainey WE 2004a The regulation of aldosterone synthase expression. Molecular and Cellular Endocrinology 217 67-74.

Bassett MH, White PC \& Rainey WE 2004b A role for the NGFI-B family in adrenal zonation and adrenocortical disease. Endocrine Research 30 567-574.

Bassett MH, Suzuki T, Sasano H, White PC \& Rainey WE 2004c The orphan nuclear receptors NURR1 and NGFIB regulate adrenal aldosterone production. Molecular Endocrinology 18 279-290.

Bird IM, Hanley NA, Word RA, Mathis JM, McCarthy JL, Mason JI \& Rainey WE 1993 Human NCI-H295 adrenocortical carcinoma cells: a model for angiotensin-II-responsive aldosterone secretion. Endocrinology 133 1555-1561.

Bird IM, Mason JI \& Rainey WE 1994 Regulation of type 1 angiotensin II receptor messenger ribonucleic acid expression in human adrenocortical carcinoma H295 cells. Endocrinology 134 2468-2474.

Bird IM, Mason JI \& Rainey WE 1998 Protein kinase A, protein kinase C, and $\mathrm{Ca}(2+)$-regulated expression of 21-hydroxylase cytochrome P450 in H295R human adrenocortical cells. Journal of Clinical Endocrinology and Metabolism 83 1592-1597.

Bollag WB, Kent P, White S, Malinova M, Isales CM \& Calle RA 2007 Characterization and phospholipase D mediation of the angiotensin II priming response in adrenal glomerulosa cells. Endocrinology 148 585-593.

Braam B, Allen P, Benes E, Koomans HA, Navar LG \& Hammond T 2003 Human proximal tubular cell responses to angiotensin II analyzed using DNA microarray. European Journal of Pharmacology 464 87-94.

Campos AH, Zhao Y, Pollman MJ \& Gibbons GH 2003 DNA microarray profiling to identify angiotensin-responsive genes in vascular smooth muscle cells: potential mediators of vascular disease. Circulation Research 92 111-118.

Casal AJ, Ryser S, Capponi AM \& Wang-Buholzer CF 2007 Angiotensin II-induced MAP kinase phosphatase-1 expression in bovine adrenal glomerulosa cells: implications in mineralocorticoid biosynthesis. Endocrinology 149 5573-5581.

Chabre O, Cornillon F, Bottari SP, Chambaz EM \& Vilgrain I 1995 Hormonal regulation of mitogen-activated protein kinase activity in bovine adrenocortical cells: cross-talk between phosphoinositides, adenosine $3^{\prime}, 5^{\prime}$-monophosphate, and tyrosine kinase receptor pathways. Endocrinology 136 956-964.

Cherradi N, Pardo B, Greenberg AS, Kraemer FB \& Capponi AM 2003 Angiotensin II activates cholesterol ester hydrolase in bovine adrenal glomerulosa cells through phosphorylation mediated by $\mathrm{p} 42 / \mathrm{p} 44$ mitogen-activated protein kinase. Endocrinology 144 4905-4915.

Christenson LK \& Strauss JF, III. 2001 Steroidogenic acute regulatory protein: an update on its regulation and mechanism of action. Archives of Medical Research 32 576-586.

Cote M, Muyldermans J, Chouinard L \& Gallo-Payet N 1998 Involvement of tyrosine phosphorylation and MAPK activation in the mechanism of action of ACTH, angiotensin II and vasopressin. Endocrine Research 24 415-419.

Cowell IG 2002 E4BP4/NFIL3, a PAR-related bZIP factor with many roles. BioEssays 24 1023-1029.

Crawford PA, Sadovsky Y, Woodson K, Lee SL \& Milbrandt J 1995 Adrenocortical function and regulation of the steroid 21-hydroxylase gene in NGFI-B-deficient mice. Molecular and Cellular Biology 15 4331-4316.

Enyeart JJ, Boyd RT \& Enyeart JA 1996 ACTH and AII differentially stimulate steroid hormone orphan receptor mRNAs in adrenal cortical cells. Molecular and Cellular Endocrinology 124 97-110.

Fernandez PM, Brunel F, Jimenez MA, Saez JM, Cereghini S \& Zakin MM 2000 Nuclear receptors Norl and NGFI-B/Nur77 play similar, albeit distinct, roles in the hypothalamo-pituitary-adrenal axis. Endocrinology 141 2392-2400.

Gallo-Payet N \& Payet MD 1989 Excitation-secretion coupling: involvement of potassium channels in ACTH-stimulated rat adrenocortical cells. Journal of Endocrinology 120 409-421. 
Gazdar AF, Oie HK, Shackleton CH, Chen TR, Triche TJ, Myers CE, Chrousos GP, Brennan MF, Stein CA \& La Rocca RV 1990 Establishment and characterization of a human adrenocortical carcinoma cell line that expresses multiple pathways of steroid biosynthesis. Cancer Research 50 5488-5496.

Gu J, Wen Y, Mison A \& Nadler JL 2003 12-Lipoxygenase pathway increases aldosterone production, $3^{\prime}, 5^{\prime}$-cyclic adenosine monophosphate response element-binding protein phosphorylation, and p38 mitogen-activated protein kinase activation in H295R human adrenocortical cells. Endocrinology 144 534-543.

Guillon G, Trueba M, Joubert D, Grazzini E, Chouinard L, Cote M, Payet MD, Manzoni O, Barberis C, Robert M et al. 1995 Vasopressin stimulates steroid secretion in human adrenal glands: comparison with angiotensin-II effect. Endocrinology 136 1285-1295.

Hajnoczky G, Varnai P, Buday L, Farago A \& Spat A 1992 The role of protein kinase-C in control of aldosterone production by rat adrenal glomerulosa cells: activation of protein kinase-C by stimulation with potassium. Endocrinology 130 2230-2236.

Herbert J 1996 Studying the central actions of angiotensin using the expression of immediate-early genes: expectations and limitations. Regulatory Peptides 66 13-18.

Honkaniemi J, Zhang JS, Longo FM \& Sharp FR 2000 Stress induces zinc finger immediate early genes in the rat adrenal gland. Brain Research 877 203-208.

Hsu HC, Zhou T \& Mountz JD 2004 Nur77 family of nuclear hormone receptors. Current Drug Targets. Inflammation and Allergy 3 413-423.

Hunyady L \& Catt KJ 2006 Pleiotropic AT1 receptor signaling pathways mediating physiological and pathogenic actions of angiotensin II. Molecular Endocrinology 20 953-970.

Kelly SN, McKenna TJ \& Young LS 2004 Modulation of steroidogenic enzymes by orphan nuclear transcriptional regulation may control diverse production of cortisol and androgens in the human adrenal. Journal of Endocrinology 181 355-365.

Lehoux JG, Fleury A \& Ducharme L 1998 The acute and chronic effects of adrenocorticotropin on the levels of messenger ribonucleic acid and protein of steroidogenic enzymes in rat adrenal in vivo. Endocrinology 139 3913-3922.

Li Y \& Lau LF 1997 Adrenocorticotropic hormone regulates the activities of the orphan nuclear receptor Nur77 through modulation of phosphorylation. Endocrinology 138 4138-4146.

Li J, Feltzer RE, Dawson KL, Hudson EA \& Clark BJ 2003 Janus kinase 2 and calcium are required for angiotensin II-dependent activation of steroidogenic acute regulatory protein transcription in H295R human adrenocortical cells. Journal of Biological Chemistry 278 52355-52362.

Liang G, Wolfgang CD, Chen BP, Chen TH \& Hai T 1996 ATF3 gene. Genomic organization, promoter, and regulation. Journal of Biological Chemistry 271 1695-1701.

Logie A, Boulle N, Gaston V, Perin L, Boudou P, Le Bouc Y \& Gicquel C 1999 Autocrine role of IGF-II in proliferation of human adrenocortical carcinoma NCI H295R cell line. Journal of Molecular Endocrinology 23 23-32.

Lu HK, Fern RJ, Luthin D, Linden J, Liu LP, Cohen CJ \& Barrett PQ 1996 Angiotensin II stimulates T-type $\mathrm{Ca}^{2+}$ channel currents via activation of a G protein, Gi. American Journal of Physiology 271 C1340-C1349.

Lu L, Suzuki T, Yoshikawa Y, Murakami O, Miki Y, Moriya T, Bassett MH, Rainey WE, Hayashi Y \& Sasano H 2004 Nurrelated factor 1 and nerve growth factor-induced clone $\mathrm{B}$ in human adrenal cortex and its disorders. Journal of Clinical Endocrinology and Metabolism 89 4113-4118.

Maxwell MA \& Muscat GE 2006 The NR4A subgroup: immediate early response genes with pleiotropic physiological roles. Nuclear Receptor Signaling 4 e002.

McKay S, de Jongste JC, Saxena PR \& Sharma HS 1998 Angiotensin II induces hypertrophy of human airway smooth muscle cells: expression of transcription factors and transforming growth factorbeta1. American Journal of Respiratory Cell and Molecular Biology 18 823-833.
McNeill H, Puddefoot JR \& Vinson GP 1998 MAP kinase in the rat adrenal gland. Endocrine Research 24 373-380.

Mehta PK \& Griendling KK 2007 Angiotensin II cell signaling: physiological and pathological effects in the cardiovascular system. American Journal of Physiology. Cell Physiology 292 C82-C97.

Mountjoy KG, Bird IM, Rainey WE \& Cone RD 1994 ACTH induces up-regulation of ACTH receptor mRNA in mouse and human adrenocortical cell lines. Molecular and Cellular Endocrinology 99 R17-R20.

Mukai K, Mitani F, Shimada H \& Ishimura Y 1995 Involvement of an AP-1 complex in zone-specific expression of the CYP11B1 gene in the rat adrenal cortex. Molecular and Cellular Biology 15 6003-6012.

Naville D, Bordet E, Berthelon MC, Durand P \& Begeot M 2001 Activator protein-1 is necessary for angiotensin-II stimulation of human adrenocorticotropin receptor gene transcription. European Journal of Biochemistry 268 1802-1810.

Otis M \& Gallo-Payet N 2006 Differential involvement of cytoskeleton and rho-guanosine $5^{\prime}$-triphosphatases in growth-promoting effects of angiotensin II in rat adrenal glomerulosa cells. Endocrinology 147 5460-5469.

Otis M, Campbell S, Payet MD \& Gallo-Payet N 2007 The growthpromoting effects of angiotensin II in adrenal glomerulosa cells: an interactive tale. Molecular and Cellular Endocrinology 273 1-5.

Pei L, Waki H, Vaitheesvaran B, Wilpitz DC, Kurland IJ \& Tontonoz P 2006 NR4A orphan nuclear receptors are transcriptional regulators of hepatic glucose metabolism. Nature Medicine 12 1048-1055.

Pirih FQ, Aghaloo TL, Bezouglaia O, Nervina JM \& Tetradis S 2005 Parathyroid hormone induces the NR4A family of nuclear orphan receptors in vivo. Biochemical and Biophysical Research Communications 332 494-503.

Rainey WE 1999 Adrenal zonation: clues from 11beta-hydroxylase and aldosterone synthase. Molecular and Cellular Endocrinology 151 151-160.

Rainey WE, Bird IM, Sawetawan C, Hanley NA, McCarthy JL, McGee EA, Wester R \& Mason JI 1993 Regulation of human adrenal carcinoma cell (NCI-H295) production of C19 steroids. Journal of Clinical Endocrinology and Metabolism 77 731-737.

Rainey WE, Bird IM \& Mason JI 1994 The NCI-H295 cell line: a pluripotent model for human adrenocortical studies. Molecular and Cellular Endocrinology 100 45-50.

Rainey WE, Saner K \& Schimmer BP 2004 Adrenocortical cell lines. Molecular and Cellular Endocrinology 228 23-38.

Romero DG, Plonczynski M, Vergara GR, Gomez-Sanchez EP \& GomezSanchez CE 2004 Angiotensin II early regulated genes in H295R human adrenocortical cells. Physiological Genomics 19 106-116.

Romero DG, Plonczynski MW, Gomez-Sanchez EP, Yanes LL \& GomezSanchez CE 2006 RGS2 is regulated by angiotensin II and functions as a negative feedback of aldosterone production in H295R human adrenocortical cells. Endocrinology 147 3889-3897.

Romero DG, Rilli S, Plonczynski MW, Yanes LL, Zhou MY, GomezSanchez EP \& Gomez-Sanchez CE 2007 Adrenal transcription regulatory genes modulated by angiotensin II and their role in steroidogenesis. Physiological Genomics 30 26-34.

Sadoshima J \& Izumo S 1993 Signal transduction pathways of angiotensin II-induced c-fos gene expression in cardiac myocytes in vitro. Roles of phospholipid-derived second messengers. Circulation Research 73 424-438.

Seta K, Nanamori M, Modrall JG, Neubig RR \& Sadoshima J 2002 AT1 receptor mutant lacking heterotrimeric $\mathrm{G}$ protein coupling activates the Src-Ras-ERK pathway without nuclear translocation of ERKs. Journal of Biological Chemistry 277 9268-9277.

Smith RD, Baukal AJ, Zolyomi A, Gaborik Z, Hunyady L, Sun L, Zhang M, Chen HC \& Catt KJ 1998 Agonist-induced phosphorylation of the endogenous AT1 angiotensin receptor in bovine adrenal glomerulosa cells. Molecular Endocrinology 12 634-644. 
Spat A \& Hunyady L 2004 Control of aldosterone secretion: a model for convergence in cellular signaling pathways. Physiological Reviews 84 489-539.

Viard I, Hall SH, Jaillard C, Berthelon MC \& SaezJM 1992 Regulation of $\mathrm{c}$-fos, $\mathrm{c}$-jun and jun-B messenger ribonucleic acids by angiotensin-II and corticotropin in ovine and bovine adrenocortical cells. Endocrinology 130 1193-1200.

Wang C, Francis R, Harirchian S, Batlle D, Mayhew B, Bassett M, Rainey WE \& Pestell RG 2000 The application of high density microarray for analysis of mitogenic signaling and cell-cycle in the adrenal. Endocrine Research 26 807-823.
Wilson TE, Mouw AR, Weaver CA, Milbrandt J \& Parker KL 1993 The orphan nuclear receptor NGFI-B regulates expression of the gene encoding steroid 21-hydroxylase. Molecular and Cellular Biology 13 861-868.

Zipfel PF, Decker EL, Holst C \& Skerka C 1997 The human zinc finger protein EGR-4 acts as autoregulatory transcriptional repressor. Biochimica et Biophysica Acta 1354 134-144.

Received in final form 24 September 2007

Accepted 18 October 2007

Made available online as an Accepted Preprint 23 October 2007 